\title{
Early Warning: Much Ado About Nothing?
}

\author{
Sharon Ruso
}

\begin{abstract}
This article provides a critical view of the history of early warning as well as existing early warming efforts. The author scrutinizes the "early earning debate," including what early warning is and who the actors might be. The paper surveys existing efforts on early warning from a critical perspective and raises many questions concerning the institutional obstacles that still need to be addressed before we can arrive at a functional early warning mechanism for the purpose of conflict prevention.

\section{Résumé}

Cet article présente sous un angle critique l'origine et l'évolution du concept d'alerte préventive et des efforts actuellement menés dans ce domaine. L'auteure analyse le débat portant sur la notion d'alerte préventive, notamment la question de la définition du concept ainsi que des acteurs qui peuvent être impliqués dans le domaine. L'article effectue un examen critique des efforts menés actuellement et soulève plusieurs questions concernant les obstacles institutionnels quidoivent encore être surmontés avant d'en arriver a établir un système d'alerte efficace en matière de prévention des conflits.
\end{abstract}

"What is early warning?" you may ask "It depends on who is asking" is an apt reply in that it conflates the definition with the question. Yet, whether we speak of early warning as the reliable forecasting of natural disasters, like hurricanes or earthquakes, or of complex emergencies like Rwanda, Liberia and the former Yugoslavia, we are all

Sharon Ruso, Head, Information Seroices, United Nations Department of Humanitarian Affairs, Geneoa.

The views expressed are the personal views of the author and are not necessarily shared by the United Nations or the Department of Humanitarian Affairs. generally talking about the ability to predict the possible movement or displacement of people as a result of nature, conflict or coercion. The real questions are: who is responsible for prediction especially in so-called complex humanitarian emergencies, and what, if anything, comes after? On the natural disaster side, responsibility and responses are fairly clearly demarcated. Not so for complex emergencies.

A recent multi-donor study, evaluating international emergency assistance to Rwanda, viewed as a failure the efforts of the international system to collect and analyze relevant data over time and to compare these to equally relevant past incidents of slaughter in Rwanda and Burundi (Adelman and Suhrke 1996). In general, the study brought together a significant amount of data as supporting evidence of the failure of many actors at different levels to live up to their responsibilities: first, to act on the warnings given and, later, to regulate the conflict in Rwanda.

Based on the view that early warning covers many issues and concerns, such as military conflict, military coups, impending humanitarian disasters such as famine and flows of refugees, slaughters and, at the extreme, genocide, the multi-donor study underlined that in the Rwanda case, all of these were involved at different stages. Throughout, the authors provide evidence of how the warnings that were made were, in some instances, interpreted in purely technical terms, as in the case of the UN Rapporteur's report in 1993 (Deqni-Ségui 1994); how both the UN system and the NGO community failed to link human rights reports to genocide; and, further, the failure on the part of key actors to acknowledge the genocide for reasons ranging from lack of interest (as on the part of the USA) through complicity (as on the part of France and Zaire). Finally, the authors answer "yes" to the question, "Did those with the capacity to prevent and mitigate the genocide have the information from which such a conclusion might be drawn?" In fact, they note that specific information about plans and conspiracies towards this end was picked up by the UN system, most significantly in the notorious "BlackFile" of January 1994 (Millwood 1995).

If the Rwanda crisis has taught us anything, it is that an effective early warning system for humanitarian emergencies should be designed around objectives which are the result of cooperation among a range of actors in the UN system and directed to initiating political action at the highest level. A number of effective early warning systems already exist, but it is as though their predictions go unnoticed. We had ample warning on the former Yugoslavia, Somalia and Rwanda, but none appears to have benefited from "early action." As for those areas in which early intervention or preventive measures were successful as a result of early warning, it is difficult to describe them since these events are not featured on $\mathrm{CNN}$.

\section{The Early Warning Debate}

A rather small group of decision makers and those who advise policymakers on early warning, conflict prevention and intervention, are generally responsible for the polemics that inform the early warning debate. Among these, though careful not to define early warning, is the group that is anxious to point out that early warning is not conflict prevention. This group chiefly comprises those who support the view that early warning is somehow related to security issues and is really an arm of traditional intelligence gathering. They are quite happy to live with the contradictions inherent in defining what early warn- 
ing is not without acknowledging the root causes of displacement and conflict prevention as major elements in this regard. This group is the most sceptical about early warning as a concept and downright cynical about the potential of any early warning system to become the centre for international alerts.

In the middle of the same spectrum stands the group that, though still sceptical, has reflected on what an early warning system, if it existed and worked, would do. They posit the view that an effective early warning system must alert the international community to impending displacement, either for pre-emptive (notice, not preventive) action or preparedness. Related to this latter view is the belief that effective early warning should identify risk fac- and exchange in the interests of early warning. Nor is there a decentralized system that could be viewed as authoritative. What we do have are opinions as to the nature and extent of conceptual frameworks through views on the need for fewer models and more implementation and methodology. ${ }^{1}$

In fact, the range of views on early warning speaks also to the heart of the reluctance of decision makers at all levels of international affairs, including the United Nations, to pay more than lip service to early warning initiatives. How, we ask, can this continue after Rwanda? The answer, in part, lies in what the multi-donor study identified as a system that does not know what its objectives are. In this regard, a number of contributing factors were identified: the lack of specialized information

\section{In fact, the range of views on early warning speaks also to the heart of the reluctance of decision makers at all levels of international affairs, including the United Nations, to pay more than lip service to early warning initiatives.}

How, we ask, can this continue after Rwanda?

tors which can then be used to identify vulnerable constituencies and lead to a more effective assessment of the need for intervention, either graduated or immediate-that is, what is the best action and at what time? Some among this group also believe that early warning can only really be accomplished outside the UN system most probably with and among the international nongovernmental sector.

At the other end of this spectrum are the groups who are actively pursuing the development of theoretical models. Some have even developed a global system of alerts and have applied them to actual situations. For now, I simply point out that the work of this group, though known and respected by some in the international community, does not receive the kind of legitimate recognition necessary for policy intervention and change. In fact, despite the work being done on a number of levels, there is no single coherent international mechanism for information collection, verification units in the field; the need for methods of prioritizing by human rights monitors in order to bring significant attention and resources to bear on important cases; the need to link early warning with contingency preparedness; and the fact that the UN system effectively lost its capacity to analyze early warning information when it disbanded the Office for Research and Collection of Information (ORCI). Other units asked to take on the role formerly played by ORCI are too operational in focus to act as the central repository for the kind of 'soft intelligence' needed to generate early warning signals for contingency planning in preventive diplomacy and peacekeeping operations. Add to all this, the cloak of secrecy and self-interest that continues to permeate national and international fora in respect of humanitarian assistance and response, and you begin to understand why there has been little significant progress in relating early warning to early action (Millwood 1995).

\section{The Actors}

Reviewing what is being done today on early warning supports what has been said about dissonance among major actors. There is a distinct lack of coordination and communication between those who are actively working in the field, and those who could profit from a reliable early warning system. On the active side, those most engaged are either academics or NGOs.

Ted Robert Gurr (Centre for International Development and Conflict Management, University of Maryland) and Barbara Harff (U.S. Naval Academy, Annapolis, MD) are leading researchers in the fields of genocide and political violence. In their work, they have come up with a series of indicators that measure and predict the degree of risk faced by various minority groups worldwide. The system of indicators developed by Gurr and his academic associates derives from a complex data set aggregation exercise, and findings come out at regular intervals in various academic journals. The work of Alex Schmidt of PIOOM (Interdisciplinary Research Programme on Root Causes of Human Rights Violations, Leiden University, Netherlands) has a similar objective, but focuses on human rights and the rule of law as the parameters for the study. Although Gurr and Schmidt have made excellent progress in their areas of research, their systems are as yet neither operational as a basis for 'soft intelligence' reporting, nor standardized in ways that would make application to the sensitive areas of political analysis feasible for most policymakers.

Gurr and Schmidt are not alone. A number of social scientists are engaged in the development of conceptual frameworks in early warning theory. Some participate in an ongoing discussion within international studies concerning the design of a system to provide the UN system with early warning of a variety of international crises. The October 1995 issue of the Mershon International Studies Review continues the debate on the develop- 
ment of an Internet-based early warning system, aspects of which are discussed below.

At the level of policy research, interest is centred in the liberal tradition of institutions like the Brookings Institute, Harvard University and the Carter Institute in Atlanta with ongoing studies of conflict resolution, peacekeeping, development, internal displacement, and related governance issues based in and on shifting statist and humanitarian norms.

NGO involvement in early warning has focused on conflict prevention. A noteworthy recent initiative, led by Kumar Rupersinghe, the Director of International Alert in London, brings together a consortium of humanitarian NGOs to discuss ways to develop coordinated modalities for conflict prevention based on an effective early warning network. Rupersinghe has tried to involve others, like Gurr and associates, and to incorporate the results of the efforts of the United Nations Inter-Agency Consultations of New Flows of Refugees and Displaced Persons that met regularly until Spring 1995. This latter group produced a list of " 41 Indicators for the Early Warning of Population Movements at a Country Level" which would profit from testing in the context of countries of origin. The hope is that the NGOs will take it on as the Inter-Agency Consultations have ceased, and there appears to be little support for their resumption without a more practical mandate than in the past.

\section{The United Nations and Early Warning}

The UN is developing two early warning systems, both within the Department of Humanitarian Affairs (DHA). The first is the Humanitarian Early Warning System (HEWS) which resides at DHA, New York. HEWS has specific responsibility for early warning and for some time has been the focus for the development of a system of reliable alerts to warn the international community of impending complex humanitarian emergencies. The unit does not produce reports for the public domain, and most of its achievements have been internal, supporting information needs on complex emergencies through, for example, the production of country profiles and daily HEWs Flashes that summarize media and internal UN reporting on hot spots worldwide.

The second UN initiative is ReliefWeb, a dynamic, interactive global information system, on the Internet, for assisting the humanitarian relief community. ${ }^{2}$ The idea is to have several categories of information available on a 24-hour basis that will cover a wide gamut of information from the emergency-specific and logistical through financial tracking and policy analysis. It is an ambitious project that will require resources, support at the highest levels by donors and the UN system, careful coordination, and multiple platform dissemination to link field operations to the global network. At the same time, it must ensure that relief agencies communicate between and among themselves in the field where it counts. Whether or not ReliefWeb will act as an early warning system will depend on the willingness of agencies to share reliable and time sensitive information from field operations. Most importantly, it will depend on how that information is translated into action. That is the critical need and the least likely to receive support at the highest levels of policy and decision making.

\section{International Cooperation}

No single organization has the capacity or resources to collect and disseminate the information required to serve humanitarian operations and the agencies involved. Consequently, cooperation at all levels, with governments, international organizations, other members of the UN family and non-governmental organizations must lead to helpful divisions of labour in regard to the collection, treatment and exchange of information. Moreover, all the relevant actors involved in the development of an effective early warning system must be brought together in order to avoid duplication, take advantage of what already exists, and introduce the principle of cooperation along with the virtue of trust in a system that is almost hopelessly cynical of its own best interests. In order that necessary steps are taken at the highest political level, agreement between and among major stakeholders must include support for early warning initiatives that speak directly to the need to link a system of reliable alerts with early action. In establishing such a system, the challenge for the international community will be linking information to policy planning and implementation. Moreover, systems that allow for rapid and frequent dissemination of such reports to major actors are as important as the knowledge that the information received is verifiable. Most importantly, the designation of a lead agency, with a mandate for early warning and conflict prevention, outside the UN system, has the potential to go the distance in successfully addressing and transcending some of the rival prerogatives inherent in the existing system which impede much-needed swift and decisive action in the face of uncertainty.

Recently, a proposal arrived from the Centre for Refugee Studies at York University in Toronto, Canada, for the development of an academic-policy consortium to create a workable, effective, economic, and cost-recoverable early warning system to deal with humanitarian emergencies, complex emergencies, and conflict areas. ${ }^{3}$ But as Peter Brecke of the School of International Affairs, Georgia Institute of Technology asserts, warning is not a politically neutral activity: "Early warning concerning natural calamities that demand humanitarian relief efforts is not problematic. Early warning of violent conflicts so that conflict-prevention activities can be initiated causes anxiety for many. Although conflict early warning may reduce the need to provide humanitarian relief, it creates pressure to act in ways that collide with state sovereignty (and in some cases cost a lot of money)." Given this reality, Brecke $(1995,322)$ contin- 